\title{
On the Fine Structure in the Infrared Spectra of Clear Natural Quartz, Amethyst, Citrine and Synthetic Quartz Crystals in the $3400 \mathrm{~cm}^{-1}$ Region
}

\author{
Dipak Chakraborty* and Gerhard Lehmann \\ Institut für Physikalische Chemie der Universität Münster \\ Z. Naturforsch. 33a, 290-293 (1978); received January 19, 1978
}

\begin{abstract}
The fractional intensities of different infrared vibration bands due to hydrogen impurities have been studied in clear natural quartz, amethyst, citrine and synthetic quartz. Integral absorptions of the different bands were found to increase linearly with total hydrogen concentration. The differences in intensity ratios for some prominent bands are distinctive for the type of quartz in some cases. The ratios of isotropic to anisotropic absorption from hydrogen impurities were found to increase with total hydrogen concentration.
\end{abstract}

\section{Introduction}

The infrared spectrum of $\alpha$-quartz in the $3400 \mathrm{~cm}^{-1}$ region has drawn the attention of many workers for a long time [1-9]. The fine structure in the infrared spectrum of clear natural quartz has been studied by Kats [3] in a more qualitative way and by Bambauer et al. [4] in more quantitative terms. Extinction coefficients of some bands, individually or in combination with those of other bands, were found to increase approximately linearly with total hydrogen concentration of the crystals [4]. For low hydrogen concentrations they were not well resolved in this study and hence could not be separated from neighboring absorptions. Kats [3] studied the infrared spectra of amethyst only qualitatively, and those for citrine were not analyzed at all. The fine structure in the infrared spectra of synthetic quartz has been discussed in detail earlier [8]. Varying proportions of the hydrogen content in amethyst, citrine and synthetic quartz crystals were found to be present as randomly oriented species [9]. They give rise to a broad absorption band and are presumed to be $\mathrm{H}_{2} \mathrm{O}$ molecules or $\mathrm{H}_{3} \mathrm{O}^{+}$ions [10]. Percentages of hydrogen concentration with isotropic absorption were also reported for these types of quartz [9]. Barns et al. [11] quoted some unpublished data indicating that the $\mathrm{H}_{2} \mathrm{O} / \mathrm{OH}$ ratios for synthetic quartz vary between 1 and 7 .

This paper presents results of a study of the fine structures in the infrared spectra of clear natural quartz, amethyst, citrine and synthetic quartz. The

* Present address: Central Glass \& Ceramic Research Institute, Jadavpur, Calcutta-700032, India.

Reprint requests to Prof. Dr. G. Lehmann, Institut für Physikalische Chemie der Universität Münster, Schloßplatz 4, D-4400 Münster. ratios of isotropic to anisotropic absorption from hydrogen were determined for these types of quartz as a function of total hydrogen content.

\section{Experimental}

The quartz crystals used in this study were from the following sources:

a) clear natural quartz from the Swiss Alps and from Brazil,

b) natural amethyst from Mexico and from Sibiria,

c) natural citrine from Mt. Bity, Madagascar, and

d) synthetic quartz crystals were grown at the Central Glass \& Ceramic Institute, Calcutta.

From these crystals plates between 1 and $5 \mathrm{~mm}$ thick were cut parallel to the $Z$ axis. Infrared spectra were recorded at $78 \mathrm{~K}$ with a Grubb-Parsons Spectromajor infrared spectrophotometer. Samples were mounted in a cryostat so that the (unpolarized) light beam passed perpendicular to the $Z$-axis. The procedure for the determination of total hydrogen concentration has been described elsewhere [8]. The ratio of isotropic to anisotropic hydrogen was determined from the areas under the broad isotropic band and under the sharp anisotropic bands of the infrared spectrum.

\section{Results and Discussion}

Table 1 lists the infrared vibration bands due to hydrogen impurities for clear natural quartz, amethyst and citrine. The average fractional intensities for each of these bands (as percentage of total anisotropic absorption) are given in each case, the ranges of hydrogen concentration are also indicated. The fractional intensities in this table allow a com- 
Table 1. The wavenumbers of infrared bands of clear natural quartz, annethyst and citrine in the region $3200 \mathrm{~cm}^{-1}$ to $3800 \mathrm{~cm}^{-1}$ at $78 \mathrm{~K}$.

\begin{tabular}{|c|c|c|c|c|c|}
\hline \multicolumn{2}{|c|}{$\begin{array}{l}\text { Clear natural } \\
\text { quartz }^{\mathrm{a}}\end{array}$} & \multicolumn{2}{|c|}{ Amethyst } & \multicolumn{2}{|l|}{ Citrine $^{\mathrm{c}}$} \\
\hline \multirow[t]{5}{*}{$\begin{array}{l}\text { Wave- } \\
\text { numbers } \\
\left(\mathrm{cm}^{-1}\right)\end{array}$} & $\begin{array}{l}\text { Frac- } \\
\text { tional } \\
\text { inten- } \\
\text { sities } \\
\text { as } \\
\text { average } \\
\text { of per- } \\
\text { centage } \\
\text { of total } \\
\text { absorp- } \\
\text { tion } \\
(\%)\end{array}$ & $\begin{array}{l}\text { Wave- } \\
\text { numbers } \\
\left(\mathrm{cm}^{-1}\right)\end{array}$ & $\begin{array}{l}\text { Frac- } \\
\text { tional } \\
\text { inten- } \\
\text { sities } \\
\text { as } \\
\text { average } \\
\text { of per- } \\
\text { centage } \\
\text { of total } \\
\text { absorp- } \\
\text { tion } \\
(\%)\end{array}$ & $\begin{array}{l}\text { Wave- } \\
\text { numbers } \\
\left(\mathrm{cm}^{-1}\right)\end{array}$ & $\begin{array}{l}\text { Frac- } \\
\text { tional } \\
\text { inten- } \\
\text { sities as } \\
\text { average } \\
\text { of per- } \\
\text { centage } \\
\text { of total } \\
\text { absorp- } \\
\text { tion } \\
(\%)\end{array}$ \\
\hline & & 3595 & 1 & 3595 & 1 \\
\hline & & 3585 & 4 & 3580 & 2 \\
\hline & & 3565 & 3 & 3565 & 3 \\
\hline & & 3550 & 3 & 3550 & 3 \\
\hline 3520 & 7 & 3520 & 4 & 3520 & 8 \\
\hline 3510 & 6 & 3500 & 6 & 3507 & 5 \\
\hline 3475 & 13 & 3475 & 11 & $\begin{array}{l}3475 \\
3460\end{array}$ & $\begin{array}{r}12 \\
4\end{array}$ \\
\hline 3440 & 11 & 3440 & 11 & 3440 & 11 \\
\hline 3430 & 5 & & & 3425 & 7 \\
\hline 3395 & 6 & 3400 & 11 & 3395 & 4 \\
\hline 3370 & 38 & $\begin{array}{l}3375 \\
3355\end{array}$ & $\begin{array}{r}10 \\
9\end{array}$ & 3370 & 18 \\
\hline 3310 & 14 & $\begin{array}{l}3305 \\
3250 \\
3205\end{array}$ & $\begin{array}{r}10 \\
9 \\
8\end{array}$ & $\begin{array}{l}3310 \\
3305 \\
3250 \\
3205\end{array}$ & $\begin{array}{r}16 \\
1 \\
4 \\
1\end{array}$ \\
\hline \multicolumn{2}{|c|}{$\begin{array}{l}1 \text { to } 140 \\
\text { Hydrogen } \\
\text { concentration } \\
\mathrm{H} / \mathbf{1 0}^{6} \mathrm{Si}\end{array}$} & \multicolumn{2}{|c|}{18 to 2850} & \multicolumn{2}{|l|}{106 to 330} \\
\hline
\end{tabular}

a average of 14 results. $\quad b$ average of 8 results.

c average of 6 results.

parison of the intensities of any two bands in the infrared spectra for each type of quartz separately. In the literature intensity ratios of only two or three prominent bands were available solely for clear natural quartz $[1,3,4]$.

Figures 1 to 3 show the relation between integral absorption of individual bands and total hydrogen concentration for clear natural quartz, amethyst and citrine resp. The integral absorptions of the bands at $3520 ; 3475 ; 3440 ; 3395 ; 3370$ and 3310 $\mathrm{cm}^{-1}$ in clear natural quartz, the integral absorptions of the bands at $3585 ; 3520 ; 3440 ; 3400$ and $3355 \mathrm{~cm}^{-1}$ in amethyst and of the bands at 3520 ; $3475 ; 3440 ; 3370$ and $3310 \mathrm{~cm}^{-1}$ in citrine all increase linearly with total hydrogen concentration.

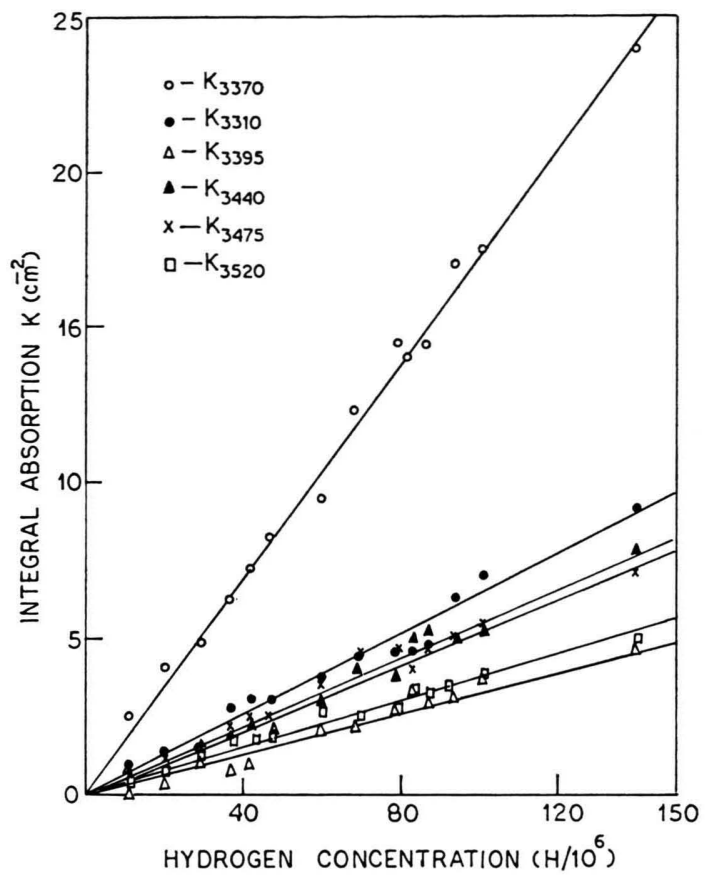

Fig. 1. Relation between integral absorption $(\mathrm{K})$ of the bands of $3520 \mathrm{~cm}^{-1}, 3475 \mathrm{~cm}^{-1}, 3440 \mathrm{~cm}^{-1}, 3395 \mathrm{~cm}^{-1}$, $3370 \mathrm{~cm}^{-1}, 3310 \mathrm{~cm}^{-1}$ and hydrogen concentration of clear natural quartz.

As evident from Table 1, clear natural quartz and citrine have some absorption bands in common, but citrine shows some additional bands not present in natural clear quartz. The intensity ratios of some typical sharp bands are distinctly different for these two types of quartz. For example, $K_{3370} / K_{3310}=2.6$ and $K_{3370} / K_{3440}=2.4$ for clear natural quartz; the

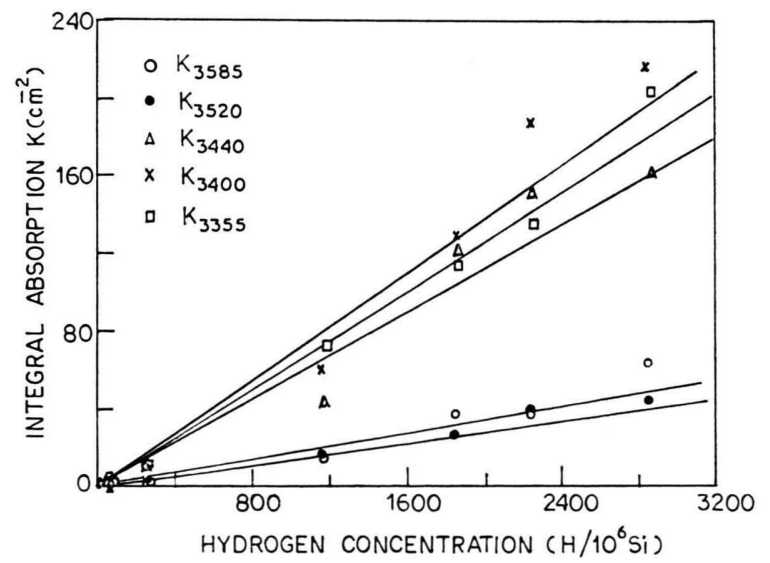

Fig. 2. Relation between integral absorption $(K)$ of the bands at $3585 \mathrm{~cm}^{-1}, 3520 \mathrm{~cm}^{-1}, 3440 \mathrm{~cm}^{-1}, 3400 \mathrm{~cm}^{-1}$, $3355 \mathrm{~cm}^{-1}$ and hydrogen concentration of amethyst. 


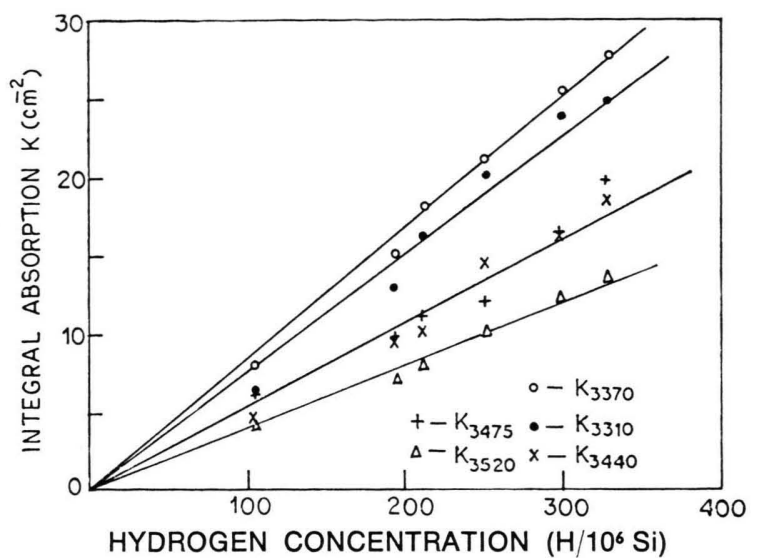

Fig. 3. Relation between integral absorption $(\mathrm{K})$ of the bands at $3520 \mathrm{~cm}^{-1}, 3475 \mathrm{~cm}^{-1}, 3440 \mathrm{~cm}^{-1}, 3370 \mathrm{~cm}^{-1}$, $3310 \mathrm{~cm}^{-1}$ and hydrogen concentration of citrine.

corresponding values for citrine are 1.1 and 1.6 resp. Smaller differences of intensity ratios are observed for common prominent bands of amethyst and synthetic quartz: $K_{3440} / K_{3400}=1$ and $K_{3400} / K_{3355}=$ 1.2 for amethyst, the ratios for synthetic quartz are 0.9 and 1.0 resp. [9].

Measurements of polarization factors for these infrared bands led us to conclude that the infrared spectra of synthetic quartz, amethyst and citrine are composed of two parts: a broad isotropic band on which sharp anisotropic bands are superimposed [9]. This broad isotropic absorption underlying the sharp anisotropic bands is shown in Fig. $4 \mathrm{~b}$ for citrine and in Fig. $4 \mathrm{c}$ for amethyst and synthetic quartz. For clear natural quartz (Fig. 4a) no such broad band seems to exist. However, the absorption spectrum of hydrogen impurities in all these types of quartz is superimposed on the spectrum of lattice vibrational overtones as pointed out by Kats [3]. The necessary corrections for this underlying lattice absorption were made in all cases as described in detail earlier [8]. For concentrations above $300 \mathrm{H} / 10^{6}$ $\mathrm{Si}$ the ratio $\mathrm{V}$ of isotropic to anisotropic hydrogen in clear natural quartz appears to be slightly larger than zero, but too few measurements could be made in this concentration range to allow a more quantitative statement to be made.

For the other types of quartz this ratio $V$ increases with total hydrogen concentration $c_{\mathrm{H}}$ in a manner that can be described by the nonlinear equation

$$
V=K_{1} \cdot c_{\mathrm{H}}+K_{2} \cdot c_{\mathrm{H}^{2}} .
$$
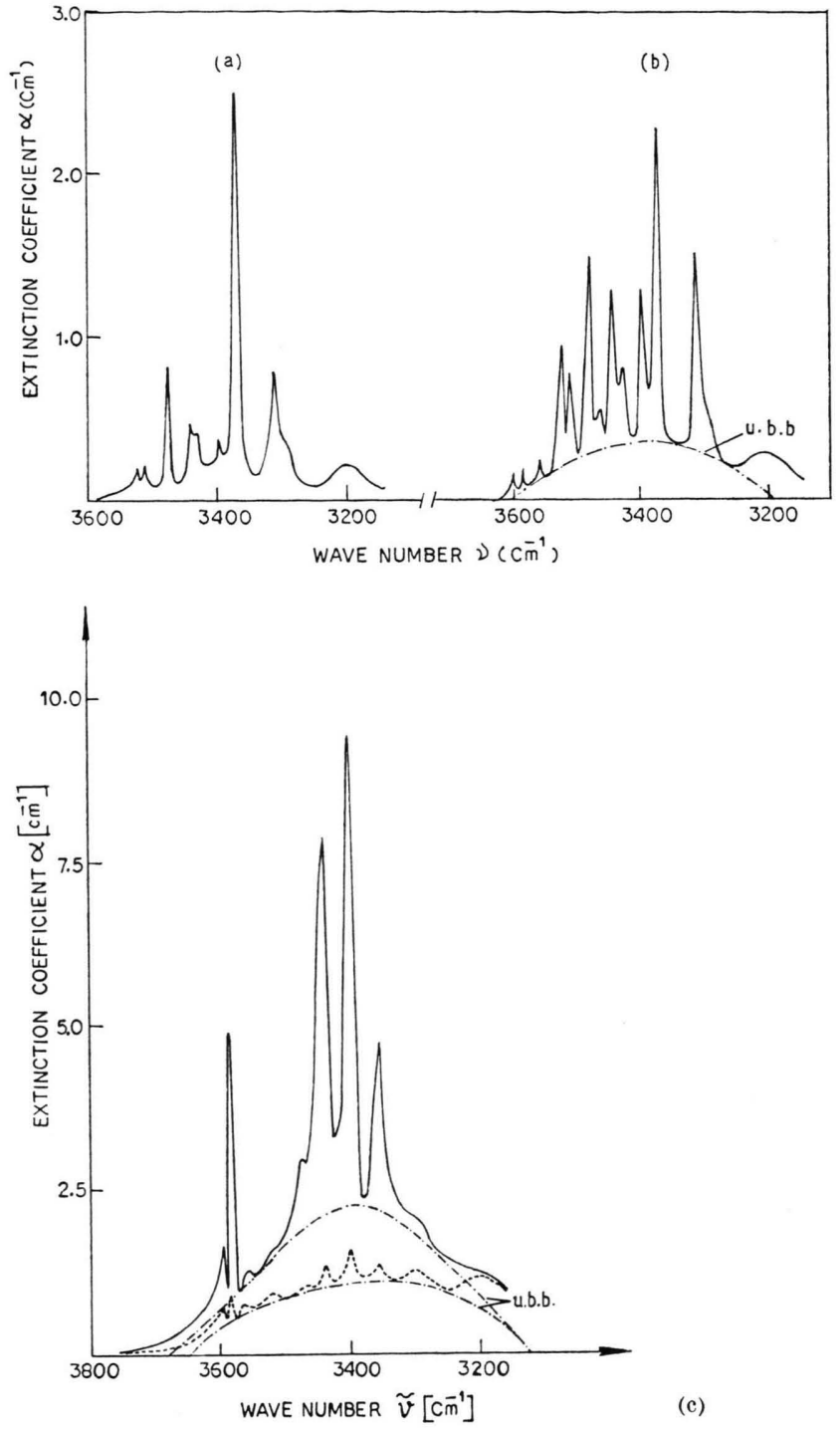

(c)

Fig. 4. IR spectra of different types of quartz recorded at $78 \mathrm{~K}$ : (a) clear natural quartz, (b) citrine, (c) —_ amethyst, $\cdots \cdots \cdots$ synthetic quartz; u.b.b. - underlying broad band.

When $c_{\mathrm{H}}$ is measured in $\mathrm{H} / 10^{6} \mathrm{Si}$ the values for $K_{1}$ and $K_{2}$ are:

$$
\begin{array}{ccc}
K_{1}=7.0 \cdot 10^{-3} \text { and } & \begin{array}{c}
K_{2}=+3.0 \cdot 10^{-6} \\
\text { for synthetic quartz }
\end{array} \\
K_{1}=1.2 \cdot 10^{-3} \text { and } & \begin{array}{c}
K_{2}=+0.12 \cdot 10^{-6} \\
\text { for amethyst and }
\end{array} \\
K_{1}=5.6 \cdot 10^{-3} \text { and } & K_{2}=-3.0 \cdot 10^{-6} \\
\text { for citrine. }
\end{array}
$$


As seen from these constants, the increase of randomly oriented hydrogen impurities is highest in synthetic quartz and levels off in citrines.

\section{Conclusions}

Although some infrared absorption bands of hydrogen impurities are common for different types of quartz, the different intensity ratios of some prominent bands in clear natural quartz and citrine can be used for their identification. For amethyst and synthetic quartz, on the other hand, the intensity ratios are too similar to allow a clear distinction. The ratios of randomly oriented hydrogen to hydrogen impurities with fixed orientations increase in a different manner with total hydrogen concentration in different types of quartz. The tacid as-

[1] D. L. Wood, J. Phys. Chem. Solids 13, 326 (1960).

[2] G. O. Brunner, H. Wondratschek, and F. Laves, Z. Elektrochem. 56, 735 (1963).

[3] A. Kats, Philips Res. Repts. 17, 133 (1962); ibid. 17, 201 (1962).

[4] H. U. Bambauer, G. O. Brunner, and F. Laves, Schweiz. Mineral. Petrol. Mitt. 43, 259 (1963).

[5] D. M. Dodd and D. B. Fraser, J. Phys. Chem. Solids 26, 673 (1965).

[6] B. D. Saksena, J. Phys. Chem. Solids 27, 465 (1966). sumption that the integral absorption per hydrogen is the same for every type of hydrogen impurity is implicitly contained in the determination of total hydrogen content. This assumption may, however, not be justified and all correlations based upon it have to be modified accordingly.

\section{Acknowledgements}

The authors wish to thank the Deutsche Forschungsgemeinschaft for support of this work. One of the authors (D.C.) is grateful to Deutscher Akademischer Austauschdienst for a scholarship and to the Director of Central Glass \& Ceramic Research Institute, Calcutta, for his kind permission to publish these results.

[7] R. N. Brown and A. Kahan, J. Phys. Chem. Solids 36, 457 (1975).

[8] D. Chakraborty and G. Lehmann, J. Solid State Chem. 17, 305 (1976).

[9] D. Chakraborty and G. Lehmann, phys. stat. sol. (a) 34, 467 (1976).

[10] R. Antrup, Diplomarbeit, Münster 1975.

[11] E. D. Barns, E. D. Kolb, R. A. Laudise, E. E. Simpson, and K. M. Kroupa, J. Crystal Growth 34, 189 (1976). 